\title{
The Role of L1 in Chinese College Students' English Learning: A Study of Kellerman's Theory of Language Transfer
}

\author{
HUANG Yan-Qing \\ School of Foreign Language, Neijiang Normal University, Sichuan, 641100, China \\ Hyq220@163.com
}

Key words: topic-prominence in Chinese; L1 transfer; psychotypology; prototypicality; L2 proficiency

\begin{abstract}
From a psycholinguistic perspective, Kellerman suggested that L1 transfer is determined by learners' perception of the distance between the native language and the target language (psychotypology), and learners' perception of certain L1 rules or items in terms of language specificity/neutrality (psychotypicality). Apart from the two factors, however, L2 learners' proficiency in the target language may also affect L1 transfer. 80 non-English first-year undergraduates participated and a language proficiency test and two questionnaires were employed in the study to investigate the influences of Chinese on English learning. The results showed that the Chinese EFL learners' perception of the specificity of Chinese topic-prominent structures, English proficiency, and the interaction between the two factors all significantly affected the transferability of the Chinese topic-prominent structures to their acquisition of the English subject-prominent structures. In contrast, no statistically significant effect was found for learners' perception of Chinese-English distance.
\end{abstract}

\section{Introduction}

The problem of transferring one's native language structure to a foreign language is well known to linguists as a general phenomenon. During the past decades, several terms were proposed by researchers to refer to the phenomenon, such as linguistic interference, the role of mother tongue, cross-linguistic influence, native language influence, language mixing and so on ${ }^{[1]}$. From a psycholinguistic perspective, Kellerman put the learner in the center of the determination of transfer, with a learner's pyschotypology and prototypicality of their NL, and actual knowledge of the TL (TL proficiency) being the key factors in determining the transferability of NL to TL.

Topic-prominence is not a new topic in the study of second language acquisition. From different typological parameters, many researchers have contrasted topic-prominence (TP) versus subject prominence (SP) to investigate questions of cross-language transfer. One set of studies claims that the process of L2 acquisition is actually characterized by an early universal topic-comment stage, independent of a learner's native language. The second set of findings claims that the early TP stage is evidence of typological transfer from L1 to L2. Although lots of studies evidenced that topic-prominent structure was transferable and did have an influence on L2 acquisition, it is rarely used to explore the transferability of Chinese to English under the framework of Kellerman' theory. So the present study, exploring the applicability of Kellerman's theory of L1 transfer through Chinese EFL learners' acquisition of English subject-prominent structure, to some extent, is new and applicable.

\section{Literature Review}

\section{1Kellerman's Theory of L1 Transfer}

Kellerman conducted a series of experiments on transferability of L1 features from the perspective of 'psycholinguistic markedness' which is also labeled as prototypicality, and has constantly modified his claims on the constraints of transfer. ${ }^{[2]}$ He argued that L1 transfer was mainly determined by two factors. One is learner's perceptions of their L1 (Prototypicality) and the 
other is learners' perception of NL-TL distance (Psychotypology).

\subsubsection{Learners' Prototypicality}

Prototypicality in this case relates to L2 learners' perceptions concerning the degree to which a structure or meaning is prototypical (central, typical, universal) versus aprototypical (noncentral, atypical, language-specific). The best known one is Kellerman's breken study, where the researcher determined which meanings and usages of the Dutch verb breken ("break") were considered by native Dutch speakers to be closest to the central, or core, meaning of the verb. In later work, Kellerman acknowledged the relationship between coreness and markedness, and eventually referred to coreness as prototypicality ${ }^{[3]}$. In an even later study, Kellerman showed that prototypicality can affect learners' intuitions about the translatability not only of word meanings, but also of grammatical structures, such as conditionals (e.g., If it would rain . . . versus If it rained ....). His studies suggested that language-neutral-perceived L1 items were more likely to be transferred to the L2 than language-specific-perceived ones. ${ }^{[4]}$

\subsubsection{Learners' Psychotypology}

Another factor constraint on L1 transfer is the distance between the native and the target language. Kellerman used the term "psychotypology" to refer to the learners' perceptions of language distance. He claimed learners' perception of NL-TL distance was important for transfer. Learners were gradually finding out what they could transfer and what they could not ${ }^{[5]}$. The closer the two languages, the more could theoretically be transferred successfully, though there were important constraints which learners appear to impose on the transferability of items. Learners' pychotypology was not fixed. Rather, it was revised as they obtained more information about the target language. Thus, Dutch learners of German may start out with the assumption that the target language is very similar to their mother tongue, but later on come to adjust this perception as they recognize the many differences.

\subsubsection{The Influences of the L2 Knowledge}

Besides, as Kellerman hypothesized, learners' actual knowledge of the TL is also a determining factor of language transfer ${ }^{[5]}$. But it is not easy to test learners' actual TL knowledge, therefore, learners L2 proficiency was employed to represent their actual TL knowledge because of the consensus on the relationship between language proficiency and language knowledge. As a result, Kellerman' theory was revised as the following: L1 transferability is determined by learners' perception of certain rules or items of their NL (Learners' prototypicality), their perception of NL-TL distance (Learners' psychotypology), and L2 proficiency. The revised model of language transfer was used in the present study.

So, Kellerman's theory can be schematized clearly as Figure1

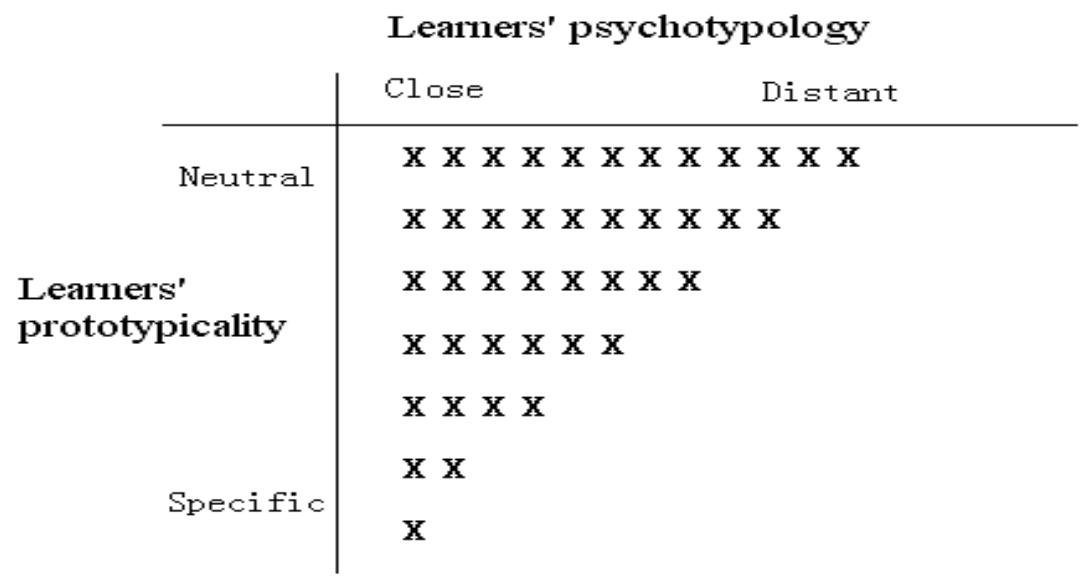

Figure 1. Schematized version of Kellerman's theory of language transfer Note. " $\mathrm{X}$ " is the possibility of transferability.

\subsection{Distinguishing Characteristics of Topic-prominent Languages}

$\mathrm{Li}$ and Thompson ${ }^{[6,7]}$ first introduced the notion of TP versus SP typology, in which English was classified as an SP language, whereas Chinese was categorized as a TP language. They also 
listed some distinguishing characteristics of TP languages. In these languages, topics are coded in the surface structure and they tend to control co-referentiality; the topic-oriented "double subject" construction is a basic sentence type, while such subject-oriented constructions as the passive and "dummy" subject sentences are rare or non-existent. Based on the previous studies ${ }^{[8,9,10,11]}$, topic coding, double- nominative construction, empty elements, non-dummy subjects, and subject-verb disagreement were chosen as the distinguishing features of topic-prominent structures in the present study.

Topic Coding: While all languages have some way of marking topics, what distinguishes topic-prominent languages is that the marking is invariant. In Chinese, topics occupy sentence initial position. For example,

(1) Zuoye, wo zuowanle (Homework, I have finished)

Duble-Nominative Constructions: In Chinese, it is common to have double nominative constructions. A pause is often inserted between the two nominatives. The first nominative is used as a topic and the second as a subject. The topic and subject in double nominative constructions can be noncoreferential as in the following example.

(2) Nei ge ren ta ma bing le. (That man his mother is sick.)

That man's mother is sick.

Empty Elements: As a TP language, Chinese allows empty elements to occur in any one of the three positions-topic, subject, and object as in the following example.

(3) Speaker A: Ni yao shu ma?

You want book?

Speaker B: Yao

Do you want a book?

Want

(I) want (it)

Non-Dummy Subject: Sentences with non-referential (Dummy) subjects never occur in Chinese. But, such constructions occur in the most highly subject-prominent languages, such as English. For example

(4) It seems that it will rain.

Subject-Verb Disagreement: subjects are grammaticalized topics, subject-verb agreement should be characteristic only of non-topic-prominent languages. English is a language strictly following the rule of subject-verb agreement. While, Chinese does not has subject-verb agreement.

\section{Research Question and Method}

\subsection{Research question}

According to Kellerman, the transferability of NL is determined by two factors. One is learners' perception of L1-L2 distance, and the other is learners' perception of certain rules or items of L1. Apart from the two factors, it seems from the literature that L2 proficiency also plays a role in determining L1 transfer. Many researchers have evidenced that the three factors mentioned above do have an influence on L1 transfer. But it is not clear whether it is true in Chinese EFL context, especially when Chinese topic-prominent structures are involved, and it is not clear how the three factors and their interaction affect L1 transfer, either. So the general research question for the present study was raised as follows:

How do the Chinese college students' prototypicality of L1 features, psychotypology, and English proficiency affect the transferability of the Chinese topic-prominent structure to their acquisition of the English subject-prominent structure?

\subsection{Subjects and Materials}

80 non-English major first-year undergraduates from Southwest University participated in the study. The subjects were from College of Chinese Language and Literature $(n=48)$ and the others were from School of History, Culture and Ethnology $(n=32)$. At the time of the study, they hadn't got a chance to take part in CET Band 4. The materials used in the study were an English proficiency test and two questionnaires. The first questionnaire was named $A$ Survey on the Authenticity of English Use, and the second questionnaire is titled A Survey on the English-Chinese Similarity and the Specificity of Chinese Syntactic Structure. 


\section{3 Procedure}

The study was conducted on Match 3, 2009, with the help of the English teacher of those subjects. The subjects were asked to finish the two questionnaires and the language proficiency test successively. The subjects were grouped as higher-proficiency group (HP Group) vs. the lower-proficiency group (LP Group), similar group (SIM Group) vs less similar group (DISSIM Group), and language-neutral group (LN Group) vs language-specific group (LS Group) respectively, according to their scores of English proficiency test, English-Chinese distance judgment and their perception of specificity of Chinese topic-prominent structure. The scores of English use authenticity judgment were considered to be the dependent variable, while the scores of Chinese-English similarity judgment, the specificity judgment of Chinese topic-prominence structure, and learners’ English proficiency were the 3 factors, for further analyses.

\section{4 Data Collection and Analysis Methods}

After the subjects finished all the materials, the test paper and questionnaires were scored. Thus, 4 sets of data were available, namely, the score of learners' judgment about the authenticity of English use, the score of English-Chinese distance perception, the score of learners' judgment of the specificity of Chinese topic-prominent structure, and the score of learners' English proficiency as well. For the purpose of the study, the first set of data was assigned as the dependent variable, while the others were grouped as factors. When all the subjects finished the tasks, 3 2-independent-samples T-test analysis and three-way analyses of variance (ANOVA) were employed to examine the collected data.

\section{Results and Discussion}

\subsection{Results}

\subsubsection{Main Effects of Prototypicality}

An independent samples test was conducted on the difference between the subjects assigned into the two levels of specificity, in terms of their scores in the authenticity judgment. The result (see Table 1.) showed that the two levels or groups had a significant difference at the .05 level, mean difference $=-8.57, \mathrm{p}=.043$.

Table 1. Independent Samples T-test Analysis of the Score of Language-specific and Language-neutral Subjects

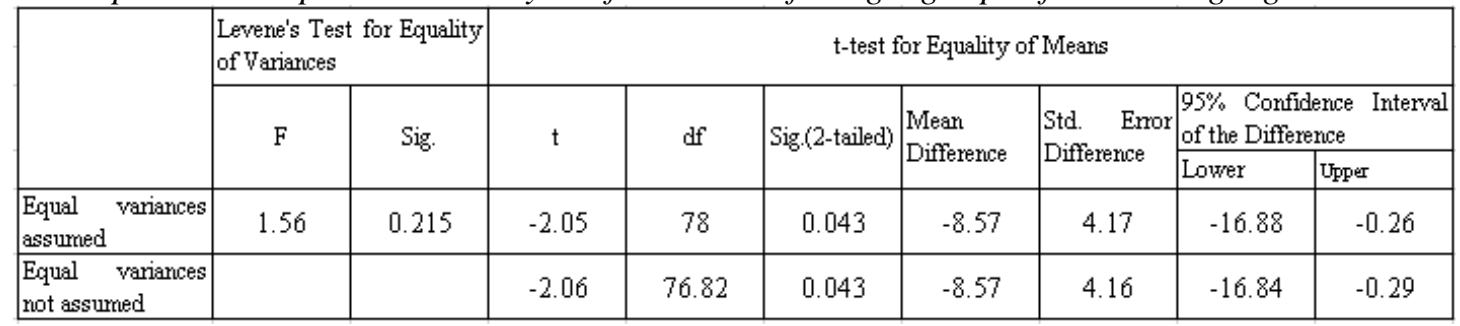

\subsubsection{Main Effects of Psychotypology}

Another independent samples $t$ test was made on the difference between the two levels of similarity (see Table 2.). The result showed that there was no significant difference in the subjects' authenticity judgment scores, mean difference $=-1.60, \mathrm{p}=.720$.

Table 2. Independent Samples T Test on the Scores of Dissimilar and Similar Groups in Authenticity Judgment

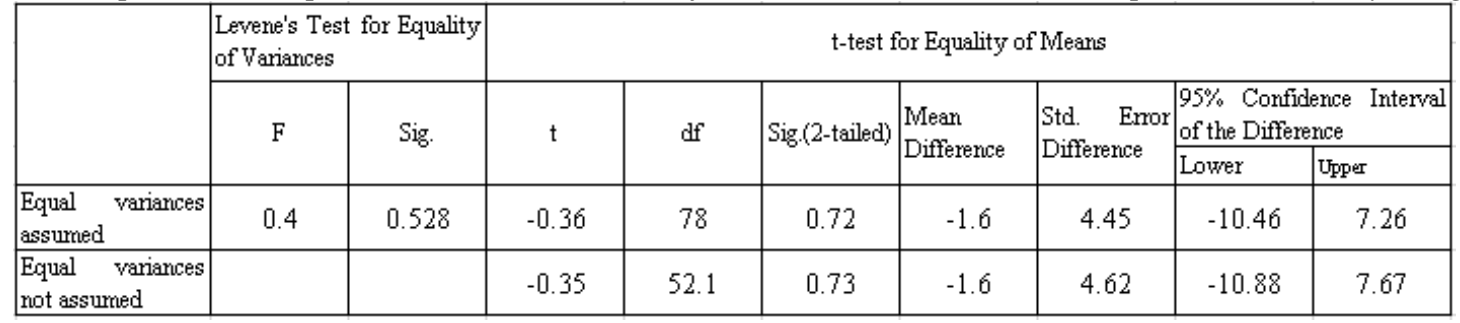

\subsubsection{Main Effects of English Proficiency}

And a third independent samples $t$ test was made on the authenticity judgment scores of the subjects grouped into the two levels of proficiency (see Table 3). The result showed that there was a 
significant difference between the two levels of subjects, at the .01 level, mean difference $=14.47$, $\mathrm{p}=.000$.

Table 3. Independent T-test on the Scores of the Low-proficiency and High-proficiency Groups in Authenticity Judgment

\begin{tabular}{|c|c|c|c|c|c|c|c|c|c|}
\hline & \multicolumn{2}{|c|}{$\begin{array}{l}\text { Levene's Test for Equality } \\
\text { of Variances }\end{array}$} & \multicolumn{7}{|c|}{ t-test for Equality of Means } \\
\hline & \multirow[t]{2}{*}{$\mathrm{F}$} & \multirow{2}{*}{ Sig. } & \multirow[t]{2}{*}{$\mathrm{t}$} & \multirow{2}{*}{ df } & \multirow{2}{*}{ Sig.(2-tailed) } & \multirow{2}{*}{\begin{tabular}{|l} 
Mean \\
Difference
\end{tabular}} & \multirow{2}{*}{$\left|\begin{array}{l}\text { Std. Error } \\
\text { Difference }\end{array}\right|$} & \multicolumn{2}{|c|}{$\begin{array}{l}95 \% \text { Confidence Interval } \\
\text { of the Difference }\end{array}$} \\
\hline & & & & & & & & Lower & Upper \\
\hline \begin{tabular}{|l|} 
Equal variances \\
assumed
\end{tabular} & 0.23 & 0.635 & 3.65 & 78 & 0 & 14.47 & 3.96 & 6.59 & 22.35 \\
\hline $\begin{array}{l}\text { Equal variances } \\
\text { not assumed }\end{array}$ & & & 3.67 & 77.5 & 0 & 14.47 & 3.95 & 6.61 & 22.33 \\
\hline
\end{tabular}

\subsubsection{Interaction Between Factors}

As shown in Table 4, there was a statistically significant interaction between the learners' perception of Chinese topic-prominence features and learners' English proficiency at .05 level, F (1, $72)=4.21, p=.044$. and there was no significant interaction between learners' perception of English-Chinese distance and learners' perception of Chinese topic-prominence features, between learners' perception of English-Chinese distance and learners' English proficiency and between learners' perception of English-Chinese distance, learners' perception of Chinese topic-prominence features, and learners' English proficiency.

Table 4. ×2 X2 ANOVA of Interaction Between Prototypicality, Psychotypology and English Proficiency

\begin{tabular}{|l|c|c|c|c|c|}
\hline \multicolumn{1}{|c|}{ Source } & $\begin{array}{c}\text { Type III } \\
\text { Sum nf }\end{array}$ & df & Mean Square & F & Sig. \\
\hline Corrected Model & 7567.85 & 7 & 1081.12 & 3.7 & 0.002 \\
\hline Intercept & 1171885.27 & 1 & 1171885.27 & 4006.51 & 0 \\
\hline L1ANDL2S * L1FEATUR & 99.99 & 1 & 99.99 & 0.34 & 0.561 \\
\hline L1ANDL2S * L2PROFIC & 27.46 & 1 & 27.46 & 0.09 & 0.76 \\
\hline L1FEATUR * L2PROFIC & 1231.27 & 1 & 1231.27 & 4.21 & 0.044 \\
\hline L1ANDL2S * L1FEATUR* L2PROFIC & 309.59 & 1 & 309.59 & 1.06 & 0.307 \\
\hline
\end{tabular}

This result thus necessitated further analyses on the significance of the effect of a certain factor upon learners' judgment of English use authenticity at each of the two conditions of the other factor. The results of these analyses are reported in Table 5 . below. Table 5 shows that at the higher English proficiency level, with an alpha level of .01, the learners' perceived specificity of Chinese topic-prominence structure had a statistically significant effect on the subjects' judgment of authentic English use, $F(1,72)=9.16>F(.01)=7.02$. In contrast, at the low-proficiency level, the learners between the two specificity conditions showed no significant difference at the .05 level, $\mathrm{F}$ $(1,72)=0.14<\mathrm{F}(.05)=3.98$.

In contrast, at the language-specific condition, the two proficiency levels revealed an extremely significant difference, $\mathrm{F}(1,72)=16.63>\mathrm{F}(.01)=7.02, \mathrm{p}<.01$. While at the language-Neutral condition, there was no significant differences between high-proficiency and low-proficiency groups. 
Table 5. Analysis on Interaction Between Learners'Perception of Chinese Topic-prominence Structure and English Proficiency

\begin{tabular}{|c|c|c|c|c|c|c|c|}
\hline & Sources & $\begin{array}{c}\text { Sum of } \\
\text { Squares }\end{array}$ & df & $\begin{array}{c}\text { Mean } \\
\text { Square }\end{array}$ & F & F.05 & F.01 \\
\hline \multirow{2}{*}{ Specificity } & High & 2678.94 & 1 & 2678.94 & $9.16^{* *}$ & 3.98 & 7.02 \\
\cline { 2 - 8 } & Low & 42.23 & 1 & 42.23 & 0.14 & & \\
\hline \multirow{2}{*}{ Proficiency } & Neutral & 575.61 & 1 & 575.61 & 1.97 & & \\
\cline { 2 - 8 } & Specific & 4864.06 & 1 & 4864.06 & $16.63^{* *}$ & & \\
\hline & Error & 21059.64 & 72 & 292.49 & & & \\
\hline
\end{tabular}

\subsection{Discussion}

The result indicated that L1 features perceived as language-neutral are more likely to be transferred and those that are perceived as language specific are less likely to be transferred. This result was similar to what was reported in Kellerman's studies, and it further evidenced that learners' prototypicality of L1 features does have an effect on the transferability of L1.

On the contrary, the result also demonstrated that learners' psychotypology is not a determinate factor of L1 transferability. It did not support Kellerman's study in 1977 and 1979, and it went against his claim that "an L2 perceived as 'close' will boost the likelihood transfer, an L2 perceived as 'distant' will depress it”. The differences may have been caused by two factors. One is that Kellerman's study was based on learners' intuition of translatability. Though his result showed that Dutch learners were more likely to translate "brekens" into German (a language close to Dutch) than to English (a language more distant from Dutch), whether learners would actually do that in learning was in question. The other is that Kellerman's study involved two foreign languages, German and English; as a result, learners might have made a comparison between the two languages, and then decided the degree of transferability to the two languages. Unlike Kellerman's studies, only one foreign language, English, was involved in the present study, which might have made the effect of psychotyology less significant as in Kellerman's studies.

\section{Conclusion}

The main findings of the study are summarized as follows.

First, learners' perception of language distance does not have an effect on the transferability of L1 structure to the acquisition of corresponding L2 structure. Second, learners' prototypicality, i.e., how learners organize his/her mother tongue, does have an effect on the transferability of L1 structure to the acquisition of corresponding L2 structure. Third, EFL learners' L2 proficiency does affect the transferability of L1 structure to the acquisition of corresponding L2 structure. Fourth, interaction does exist between learners' psychotypology and L2 proficiency. The successful EFL learners perform well in controlling the transferability of certain L1 structures to the acquisition of corresponding L2 structures. The findings of the study have implications for EFL teaching and learning in China. For those L1 features which can facilitate L2 learning, language-similar perception should be reinforced. And for those that inhibit L2 learning, language-specific perception should be emphasized, so that negative transfer could be avoided.

\section{Acknowledgments}

This work was financially supported by Neijiang Normal University’s Scientific Research Program "A Study of Kellerman’s Theory of Language Transfer(13SB08)".

\section{References}

[1] T. Odlin. Cross-linguistic influence. In C. J. Doughty \& M. H. Long (Eds.), The handbook of second language acquisition (pp.436-486). Oxford: Blackwell,2004.

[2] R. Ellis. The study of second language acquisition. Oxford: Oxford University Press,1994.

[3] E. Kellerman. Now you see it, now you don’t. In S. Gass \& L. Selinker (Eds.), Language 
transfer in language learning. Rowley: Newbury House Publishers, 1983, pp.112-134.

[4] E. Kellerman. The imperfect conditional. In K. Hyltenstam and L. Obler (Eds.), Bilingualism across the lifespan: Aspects of acquisition, maturity and loss. Cambridge, UK: Cambridge University Press, 1989, pp. 87-115.

[5] E. Kellerman. Transfer and non-transfer: Where we are now. Studies in Second Language Acquisition, 1979(2), 37-57.

[6] Li, C. N., \& S. A. Thompson. Subject and topic: A new typology of language. In Charles N. Li (Ed.), Subject and topic. New York: Academic Press, 1976, pp. 457-489.

[7] Li, C. N., \& S. A. Thompson. Mandarin Chinese: A functional reference grammar. Berkeley: University of California Press,1981.

[8] Jung, E. H. Topic and subject prominence in interlanguage development. Language Learning, 2004(4), 713-738.

[9] J. W. Fuller \& J. K. Gundel. Topic-prominence in interlanguage. Language Learning, 1987 (1), 1-18.

[10] Cai, J.-T. The influence of Chinese topic-prominent features on Chinese EFL learners' compositions. Foreign Language Teaching and Research, 1998(4), 17-21.

[11] Cai, J.-T.. Language transfer and topic-prominence. Journal of PLA University of Foreign Languages, 1998(6), 13-17. 